See Article page 1014.

\section{Commentary: Avoiding the Rorschach trap in the evaluation of surgical skill}

\author{
J. W. Awori Hayanga, MD, MPH, and \\ Alper Toker, MD
}

The objective adjudication of surgical skills is a complex endeavor and could fall prey to a multitude of hurdles from both an objective and subjective perspective. The evaluation of these skills may ostensibly be characterized into 3 categories: technical, patient management, and judgment. In this article, Dr Carpenter appropriately points out that the appraisal of surgical capability is equally as challenging as the acquisition of the very surgical skills being evaluated. ${ }^{1}$ Admittedly, technical ability, the handling of tissue, tying knots, and manipulating robotic and endoscopic instruments can be broken down into components and be subjected to accurate, objective evaluation, comparatively speaking. This is also true for cognitive appraisal of clinical knowledge, which can be tested in written format. The difficulty, however, is in how to measure judgment and how to maintain this appraisal of judgment longitudinally through the span of a surgeon's career. How should we best proceed with evaluating the higher function that marries technical and cognitive performance in a clinical landscape that is itself peppered with potent distracting forces fueled by explicit and implicit bias and profoundly influenced by past and present experiences, each of which exerts a vast effect on inter-rater judgment and perception?

Not only does the practice of surgery bear closer a resemblance to an art than a science, but evaluating surgical

\footnotetext{
From the Department of Cardiovascular and Thoracic Surgery, West Virginia Medicine, Morgantown, WVa.

Disclosures: The authors reported no conflicts of interest.

The Journal policy requires editors and reviewers to disclose conflicts of interest and to decline handling or reviewing manuscripts for which they may have a conflict of interest. The editors and reviewers of this article have no conflicts of interest.

Received for publication Jan 19, 2022; revisions received Jan 19, 2022; accepted for publication Jan 19, 2022; available ahead of print Jan 22, 2022.

Address for reprints: J. W. Awori Hayanga, MD, MPH, Department of Cardiovascular and Thoracic Surgery, West Virginia University, 1 Medical Center Dr, Morgantown, WV 26506 (E-mail: jeremiah.hayanga@wvumedicine.org).

J Thorac Cardiovasc Surg 2022;164:1017

$0022-5223 / \$ 36.00$

Copyright (C) 2022 by The American Association for Thoracic Surgery

https://doi.org/10.1016/j.jtcvs.2022.01.024
}

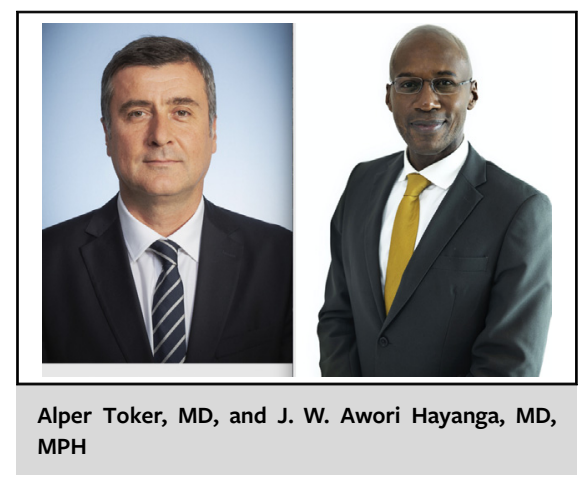

CENTRAL MESSAGE

Evaluation of surgical skill should

be objective and reproducible.

practice is almost entirely an art. We are reminded of the adage, "Good judgment comes from experience; experience comes from bad judgment." The maintenance of board certification in the American context is mainly predicated on measuring clinical judgment and medical knowledge of diagnostic and therapeutic options. It is not a simple task, nevertheless, to identify subtle changes in improvement or progression and, worse, even harder to identify and prove more substantial changes resulting from deterioration in judgment. One thing that remains certain is that the fair adjudication of surgical skill, judgment, or cognitive performance should draw upon a spectrum of opinion from a range of observers using as objective a set of criteria as is possible to resist the influences of bias, misperception, and self-centric motivations. These latter influences are naturally occurring phenomena that characterize how the brain functions at baseline in the appraisal of people and situations alike. Perhaps one solution would be to include appropriately risk-adjusted outcomes measured longitudinally over the life and career of each surgeon. Perhaps the addition of outcome measurement would more objectively shed light on the structure and processes accompanying those very outcomes. Using this Donabedian approach, we may more effectively prevent the process of evaluation from devolving into a Rorschach test.

\section{Reference}

1. Carpenter AJ. Evaluation of surgical capabilities is complex but necessary. $J$ Thorac Cardiovasc Surg. 2022;164:1014-6. 